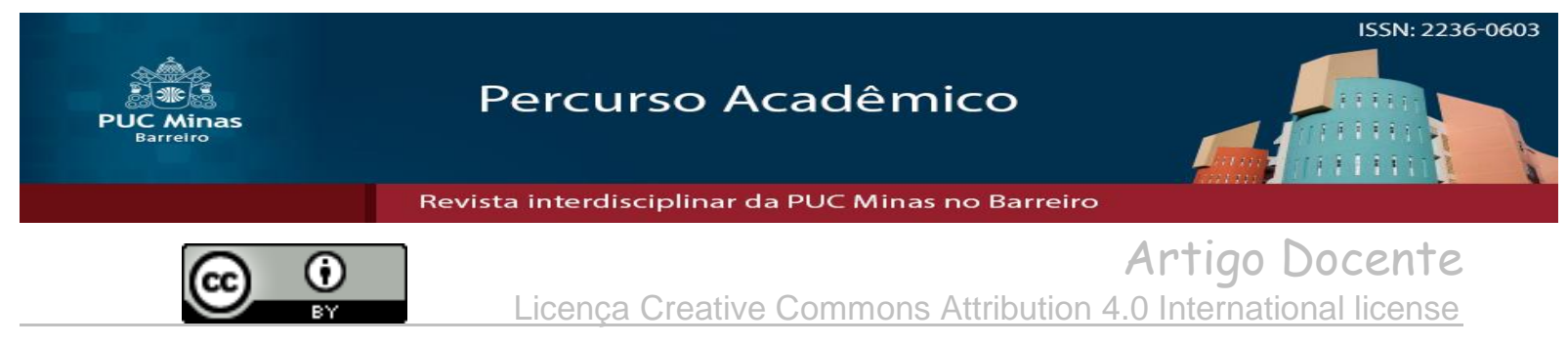

\title{
O homem e o sonho: Darcy Ribeiro, 1922-1997. Brasil, 1500...
}

The man's dream: Darcy Ribeiro, 1922. Brazil, 1500...

\author{
Marileide Lázara Cassoli ${ }^{1}$
}

\begin{abstract}
Resumo
A leitura de $O$ povo brasileiro nos instiga a pensar sobre esse gigantesco quebra-cabeças constituído pelo Brasil e o seu povo. Para Darcy Ribeiro, desvelar o processo que consolidou as desigualdades historicamente construídas em nosso país responderia à incógnita que o motivou a escrever diversos estudos sobre o processo de formação de nosso povo: Por que o Brasil não deu certo? Um tema tão antigo quanto atual, elevar o Brasil ao patamar das nações civilizadas fez parte do imaginário das elites nacionais na condução da vida política do país em vários momentos de sua história. Compreender as razões de nosso desenvolvimento desigual e pensar nas perspectivas de auto-superação que se abrem aos povos considerados mais atrasados, nortearam não apenas a elaboração de $O$ povo brasileiro, assim como, conduziu à publicação de uma série de estudos sobre o processo de formação dos povos americanos. A educação, caminho a ser construído e trilhado nessa empreitada, foi o sonho que norteou as ações deste intelectual que acreditava ser esta a via para que o Brasil "desse certo". Buscamos, aqui, discutir essas questões a partir das proposições contidas nesta obra.
\end{abstract}

Palavras-chave: Darcy Ribeiro. Educação. Cidadania.

\begin{abstract}
The book $O$ povo brasileiro instigates us to reflect about the puzzle constituted by Brazil and its people. For Darcy Ribeiro, unveiling the process that consolidated historically inequalities in our country motivated him to write several studies about the process of our people formation and respond a difficult question: Why did Brazil fail? A theme as old as current, raising Brazil to the level of civilized nations was a plan of our national elites and conducted the country's political life at several times in our history. The author aims to understand the reasons for our uneven development. At the same time, he was thinking about the perspectives of self-overcoming that are open to the people considered backward. Concerned about these questions he wrote $O$ povo brasileiro, and several studies about american people historical formation. Darcy Ribeiro believed in education like a path to be built the only way to do Brazil "works". This dream guided his political and intellectual actions. We seek in this article discuss these issues from the author's propositions.
\end{abstract}

Keywords: Darcy Ribeiro. Education. Citizenship.

\footnotetext{
Artigo recebido em 10 de Novembro de 2016 e aprovado em 03 de Abril de 2017.

${ }^{1}$ Doutora em História Social da Cultura pela UFMG/2015. Professora da FAE/UEMG. Pós-Doutoranda em História pelo ICHS/UFOP. E-mail: ml.meyer@uol.com.br.
} 


\section{Introdução}

Portanto, não se iluda comigo, leitor. Além de antropólogo, sou homem de fé e de partido. Faço política e faço ciência movido por razões éticas e por um fundo patriotismo. Não procure aqui, análises isentas. Este é um livro que quer ser participante, que aspira a influir sobre as pessoas, que aspira a ajudar o Brasil a encontrar-se a si mesmo. (RIBEIRO, 2006, p. 16).

Definir um homem e a sua obra é tarefa hercúlea. Ao fazê-lo, incorremos muitas vezes em equívocos que podem ir da crítica vazia ao louvor exacerbado. Darcy Ribeiro, entretanto, ao escrever o trecho acima, no prefácio de sua obra $O$ povo brasileiro, poupa-nos de cometer quaisquer destes equívocos. O homem, o intelectual e a obra se encontram aí definidos coerentemente em sua trajetória. Seja na sua atuação como etnólogo, educador ou político, todo o seu legado tem a marca indelével do conhecer para intervir. Conhece-te a ti mesmo e, a partir dessa máxima, encontra-te a ti mesmo.

Nosso objetivo neste texto é, a partir da leitura de $O$ povo brasileiro, pensar a contribuição de Darcy Ribeiro para a compreensão desse gigantesco quebra-cabeças que é o Brasil e o seu povo. Obviamente não pretendemos esgotar as possibilidades de interpretação oferecidas pelo autor, e sim discutir o quanto a peça fundamental para a composição desta montagem está longe de ser "encaixada".

\section{Desenvolvimento}

Promover o encontro do povo brasileiro consigo mesmo foi a tarefa a que se propôs Darcy Ribeiro. O sonho de construção da Nação foi precedido pela tarefa prática de desvelar o nascimento da mesma, de buscar as suas origens e de consolidar uma identidade comum ao "ser brasileiro"; enfim, fazer uma leitura pessoal de nossa história sem qualquer preocupação em ocultar suas idiossincrasias ou deixar de explicitar o seu ideal de Brasil.

O Brasil é já a maior das nações neolatinas, pela magnitude populacional, e começa a sê-lo também por sua criatividade artística e cultural. Precisa agora a sê-lo no domínio da tecnologia da futura civilização, para se fazer uma potência econômica, de progresso autossustentado. Estamos nos construindo na luta para florescer amanhã como uma nova civilização, mestiça e tropical, orgulhosa de si mesma. (RIBEIRO, 2006, p. 411).

Ideal em construção, perspectiva esperançosa e positiva dos que estão se fazendo e saindo da "ninguendade" para se autoconhecerem. Paradoxalmente, o que motivou o intelectual a pensar o país foi uma percepção negativa desse território: "Por que o Brasil 
não deu certo?" Entender as razões de seu desenvolvimento desigual e pensar nas perspectivas de auto superação que se abrem aos mais atrasados, nortearam não apenas a elaboração de $O$ povo brasileiro como também conduziram à publicação de uma série de estudos sobre o processo de formação dos povos americanos ${ }^{2}$. Estudos estes que acabaram por relegar a publicação de $O$ povo brasileiro a um ostracismo de 30 anos, transformando-o em um livro síntese da trajetória intelectual de Darcy Ribeiro.

Para um povo único em suas origens e em sua história, fez-se necessário lançar mão de uma ferramenta teórica que explicasse essa originalidade e que permitisse situar o Brasil não apenas em relação à sua própria história, mas inserido na história da humanidade. Editado pela primeira vez em 1968, O Processo Civilizatório, ao adotar a perspectiva de interação entre as sociedades diversamente desenvolvidas, rompe com a visão eurocêntrica, etapista e linear, na qual as sociedades são encaixadas no esquema de sequências evolutivas e sucessivas que iriam do subdesenvolvimento ao desenvolvimento.

Trabalhando com os conceitos de aceleração evolutiva e atualização histórica ${ }^{3}$, Darcy Ribeiro compreende as sociedades avançadas e atrasadas como polos interativos de um mesmo sistema socioeconômico, no qual estas perpetuariam suas posições relativas, ao mesmo tempo, opostas e coetâneas. Marcado por três grandes processos de atualização histórica, o Brasil se encontraria, ao final dos anos 1960, entre o grupo de nações atrasadas. Tendo surgido como provedor colonial de bens para o mercado mundial, por meio de sua população nativa (índios) ou importada (africanos), mantinham-se os brasileiros, no século $\mathrm{XX}$, como um povo novo e velho ${ }^{4}$ que se viabilizava apenas como proletariado externo. Em última instância, esta é uma crítica do autor ao processo de industrialização e ao seu fracasso como elemento de civilização no Brasil. Conduzido por uma elite associada às corporações multinacionais, os esforços de

\footnotetext{
${ }^{2}$ Ver: RIBEIRO, Darcy. O processo civilizatório: etapas da evolução sócio-cultural. Rio de Janeiro: Civilização Brasileira, 1968; RIBEIRO, Darcy. As Américas e a civilização: a integração das populações indígenas no Brasil moderno. Rio de Janeiro: Civilização Brasileira, 1970.

${ }^{3}$ Os povos marcados pelo processo de "aceleração evolutiva" são aqueles que existem para si mesmos e renovam autonomamente seu sistema produtivo e reformam suas instituições sociais. Já o processo de "atualização histórica", compreende povos atrasados na história que são engajados compulsoriamente em sistemas mais evoluídos tecnologicamente, perdem sua autonomia ou sofrem a destruição de sua identidade étnica. O grau de eficiência produtiva entre as sociedades contemporâneas é o critério definido pelo autor para classificar as sociedades em atrasadas ou avançadas. (RIBEIRO, 1968).

${ }^{4}$ Sobre os conceitos: povo novo e povo velho ver Ribeiro (2006).
} 
modernização levados adiante por esse segmento visavam apenas à preservação de seus interesses e ao atrelamento do país à civilização pós-industrial como povo dependente.

Um tema tão antigo quanto atual, elevar o Brasil ao patamar das nações civilizadas fez parte do imaginário das elites nacionais na condução da vida política do país em vários momentos de sua história. Mais ainda, alimentou um projeto de unidade nacional, territorial e ideológico, com vistas a legitimar a atuação dessa elite na condução desse processo. Ao final do século XIX, sessenta anos após a Independência, o Brasil ainda procurava definir-se como Nação.

A anistia, o esquecimento da escravidão; a reconciliação de todas as classes; a moralização de todos os interesses; a garantia da liberdade dos contratos; a ordem nascendo da cooperação voluntária de todos os membros da sociedade brasileira: essa é a base necessária para reformas que alteiam o terreno político em que esta existiu até hoje. O povo brasileiro necessita de outro ambiente, de desenvolver-se e crescer em meio inteiramente diverso. (NABUCO, 2000, p. 171).

Em agosto de 1883, O Abolicionismo, escrito por Joaquim Nabuco, apontava como o maior e indiscutível obstáculo à ascensão do Brasil ao pódio das nações ditas civilizadas, a sobrevivência da escravidão, ainda no final do século XIX. Raiz de todos os males e vícios que corrompiam a sociedade e suas instituições, eliminá-la significava o fim da excepcionalidade negativa do país frente ao mundo civilizado a que almejava não apenas inserir-se como também ser reconhecido como um par. ${ }^{5}$

\footnotetext{
${ }^{5} \mathrm{O}$ parâmetro de civilização referia-se especificamente à França e à Inglaterra. A escravidão, pela sua própria natureza, brutalizava o escravo e contaminava moralmente a sociedade brasileira, corrompendo a família e gerando uma massa de libertos pouco afeitos ao trabalho. Os debates da condução do problema da escravidão ganharam força e mantiveram-se na pauta das discussões políticas, econômicas e jurídicas durante todo o século XIX, notadamente em sua segunda metade, com a extinção definitiva do tráfico negreiro internacional. Relacionando a escravidão e a construção da nação a partir da trajetória política de José Bonifácio, ver SILVA, Ana Rosa Cloclet da. Construção da Nação e escravidão no pensamento de José Bonifácio (1783-1823). Campinas: Editora da Unicamp, 1999. p. 141-218; as imagens construídas sobre o escravo pelos abolicionistas brasileiros e sua associação aos vícios e à preguiça que marcava a sociedade brasileira de então são analisadas por AZEVEDO, Célia Maria Marinho de. Abolicionismo: Estados Unidos e Brasil, uma história comparada (século XIX). São Paulo: Annablume, 2003. p. 99-146; em SCHWARCZ, Lilian Moritz. O Espetáculo das raças: cientistas, instituições e questão racial no Brasil, 1870-1930. São Paulo: Companhia das Letras, 2001. p. 11-22, é abordada a questão da mestiçagem e sua responsabilidade no atraso ou mesmo inviabilidade da nação; sobre escravidão e formação do mercado de trabalho livre no Brasil ver GEBARA, Ademir. O mercado de trabalho livre no Brasil. São Paulo: Editora Brasiliense, 1986; CHALHOUB, Sidney. Trabalho, lar e botequim: o cotidiano dos trabalhadores do Rio de Janeiro da Belle Époque. São Paulo: Editora Brasiliense, 1986; LAMOUNIER, Maria Lúcia. Da escravidão ao trabalho livre: a lei de locação de serviços de 1879. São Paulo: Papirus, 1988; COSENTINO, Daniel do Val. O olhar das autoridades: projetos e processo para a transição do trabalho escravo para o trabalho livre na Província de Minas Gerais. Apresentação. In: XIII Seminário sobre a Economia Mineira, 2009, Diamantina, Minas Gerais. Anais do XIII Seminário sobre a Economia Mineira. Diamantina CEDEPLAR - UFMG, 2008.
} 
Intérprete de seu próprio tempo, Nabuco propõe-se a pensar a Nação a partir dela mesma, subvertendo a lógica de que o papel da história é organizar o passado a partir dos questionamentos impostos pelo presente. Para ele, a linha da história seguia do presente para o futuro, eliminar a mancha da escravidão, que ainda persistia no país, era o único caminho viável para que o Brasil seguisse adiante, linearmente, em direção ao progresso e à civilização. Impunha-se com urgência organizar o presente a partir dele mesmo. Perscrutar o passado torna-se uma mera formalidade de compreensão do caminho percorrido até o ponto em que as mazelas do presente apontam para um futuro sombrio.

Palavras caras e representativas de um mundo ao qual a jovem nação brasileira almejava pertencer, reforma, moralização, cooperação e ordem, foram, no decorrer do século XIX, incorporadas aos discursos e ações que nortearam a construção de uma sociedade e de um Estado Nacional à semelhança das "Nações Civilizadas". Nesse processo, os setores dirigentes ${ }^{6}$ buscavam ainda consolidar a instituição monárquica e garantir a manutenção harmoniosa da ordem interna, ou seja, a escravidão, o controle sobre a terra e a exclusão política dos setores populares; construindo, assim, sua identidade como classe social ao fundar o Império do Brasil. Os grupos dirigentes se confrontavam na escolha do caminho a ser seguido nesse processo inicial de construção da Nação, no qual, o grau de centralização do poder, associado à manutenção da unidade territorial, constituíam-se em pontos fulcrais ${ }^{7}$.

\footnotetext{
${ }^{6}$ Por setores dirigentes entendemos aqui não apenas a elite política, que se confundia muitas vezes com a elite econômica (agricultura escravista de exportação), mas também a burocracia estatal composta segundo Carvalho (2008, p. 40-41), por aqueles "elementos mais dinâmicos que não encontravam espaço de atuação dentro dessa agricultura". É importante destacar que tal "diversidade" entre os elementos da burocracia acaba por conceder à elite política "certa margem de liberdade e ação". Para o autor, no último quartel do século XIX, a homogeneidade inicial da elite se rompe pela grande redução do número de funcionários públicos e pelo aumento dos advogados. Além desse aspecto, as próprias mudanças provocadas pela expansão do processo de urbanização e ascensão de novos grupos sociais nas últimas décadas do século XIX acabaram por pressionar por uma maior representação de interesses dentro do Estado contribuindo para novos arranjos políticos. Ver ainda Schwarcz (2001, p. 24-25) em que a autora destaca a homogeneidade dos intelectuais brasileiros e sua vinculação às elites econômico-financeiras do país, fato que se alteraria na segunda metade do século XIX em função de diferenças regionais e profissionais. É importante ressaltar a discussão de Hespanha (2007, p. 39-44) acerca da história das elites, embora este não seja o ponto central deste trabalho, no qual, para o autor, a nova história do poder, sua microfísica e inserção em todos os nichos do tecido social, traria à tona, ao lado da história das elites, os grupos subalternos. Para o nosso trabalho, as análises acerca das elites dirigentes se vinculam diretamente, não apenas às discussões sobre o encaminhamento da questão escravista, mas a contrapartida de ação de escravos e senhores às ações resultantes desse encaminhamento.

${ }^{7}$ Enquanto a unidade territorial constituía ponto pacífico entre os grupos dirigentes para consolidação da emancipação e construção da nação, o grau de centralização do poder foi objeto de disputas entre os grupos que ocupavam a cena política. Ao período regencial marcado pelo avanço liberal (Guarda
} 
A unicidade territorial passava a ser o parâmetro de homogeneidade diante da diversidade racial e dos interesses regionais, e, contraditoriamente, a escravidão, representação concreta da não liberdade, podia ser apontada como a instituição que fundamentava a recém-emancipada nação pelo seu grau de inserção entre os diversos segmentos sociais. Se havia algum traço de democracia ou de unidade interna, este residia no "enorme comprometimento do conjunto da população livre com a continuidade da escravidão". (CASTRO, 200, p. 368).

Além de seu aspecto unificador, a escravidão estava inevitavelmente associada à preservação dos interesses econômicos da grande lavoura, base da economia do país, que ganharia cada vez mais força com o desenvolvimento da cafeicultura, no decorrer da segunda metade do século XIX.

O entrelaçamento da economia à política transformava a salvaguarda dos interesses da agricultura na preservação dos interesses da própria nação, afinal a agricultura de exportação garantia o contato com as nações civilizadas, reintegrando o país nas linhas do comércio mundial que se expandia e fornecendo rendas para o Estado. Estas, essenciais para que se efetivasse a construção do ideal de nação ordenada e civilizada ${ }^{8}$.

A ação da Coroa, centro administrativo, nesse contexto, almejava a gestão dos diversos interesses regionais e o processamento de conflitos entre os grupos dominantes. A homogeneidade da elite era o pré-requisito para a manutenção da Ordem no caminho rumo ao Progresso e à Civilização, e na extensão desses valores para a sociedade como um todo.

A homogeneidade da elite pela educação comum na tradição do absolutismo
português e pela participação na burocracia estatal fazia com que o
fortalecimento do Estado constituísse para ela não só um valor político como
também um interesse material muito concreto. Desse modo, o objetivo da
manutenção da unidade da ex-colônia rarissimamente seria posto em dúvida
por elementos da elite nacional, talvez até mesmo independentemente de
estar essa unidade em acordo ou desacordo com os interesses dos grupos

Nacional, Código do Processo Criminal e o Ato Adicional), seguiu-se o Regresso conservador, justificando o fortalecimento das instituições em função da "anarquia", ou seja, as revoltas do período regencial, provocada pelas medidas liberais. Ver: Andrade (2007, p. 116-118).

${ }^{8}$ A instrução pública, incutindo princípios éticos e morais, e o trabalho disciplinado eram compreendidos pelos setores dirigentes como pré-requisitos na difusão da civilização como atribuições que cabiam ao Estado, assim como a montagem de um aparato que garantisse a expansão da burocracia e do monopólio da força, por isso a defesa dos interesses da grande lavoura como interesses do próprio Estado imperial. Segundo Carvalho (2008), 70\% das rendas do governo-geral, por meio dos impostos de importação e exportação, eram provenientes da agricultura de exportação. É importante ressaltar ainda que a escravidão permeava a agricultura para o mercado interno e o meio urbano. 
econômicos dominantes. José Bonifácio, por exemplo, voltou para o Brasil com a ideia formada de criar na América um grande império, coincidisse esse objetivo ou não com interesses básicos como a manutenção da escravidão. Ele resistiu, aliás, à pressões inglesas em favor de medidas abolicionistas com receio de que viessem colocar em perigo a unidade nacional. (CARVALHO, 2008, p. 42).

O processo de homogeneização da elite dirigente dar-se-ia, para o autor, não pelo fato de ser recrutada entre elementos dos setores dominantes da sociedade, mas pela sua socialização via educação, ocupação e carreira política, ou seja, homogeneidade ideológica e de treinamento. A homogeneidade da elite concretizava-se, dessa forma, em uma autoimagem que a transformava em representante da "boa sociedade" em oposição aos livres despossuídos e escravos. Oposição cristalizada em dois conceitos diferenciadores e determinantes da escala hierárquica social: propriedade e liberdade ${ }^{9}$.

Garantidos pela Constituição de 1824, tais conceitos distinguiam os cidadãos dos não-cidadãos, ou seja, os proprietários de si e de outrem, daqueles que não possuíam sequer a sua própria liberdade; logo os cidadãos ou a "boa sociedade" constituíam a sociedade política portadora dos pré-requisitos que a tornavam competente para o governo do Estado. O sentimento aristocrático, unificador dos grupos dirigentes ${ }^{10}$, estabelecia critérios de distinção entre a "boa sociedade" e a escória. Critérios estes que asseguravam a persistência do caráter colonial e escravista da sociedade após a emancipação política, em que a restauração dos monopólios e a expansão da riqueza constituíam objetivos vitais que os opunham ao "povo" e aos escravos.

\footnotetext{
${ }^{9}$ Outros critérios distintivos seriam o atributo racial, o grau de instrução e os vínculos pessoais estabelecidos. (MATTOS, 2004). Para os conservadores e liberais, à época da Maioridade, a liberdade estava atrelada à ordem e consequentemente à monarquia e à integridade territorial. Segundo Mattos (2004, p. 157-164), "Ficava claro também que a maior soma de liberdade estava em correspondência direta com a força do governo, isto é, o Poder Executivo", dessa forma, a soberania do Império se construía a partir da própria sociedade, a qual se submetia ao Soberano em nome da manutenção da paz e da ordem. A questão de manutenção da ordem imbricar-se-á com o próprio conceito de cidadania nas discussões acerca da formação da Guarda Nacional em 1832, já que a segurança pública era responsabilidade e dever dos bons cidadãos na garantia de seu bem-estar e proteção. (GRINBERG, 2002. p. 114).

${ }^{10}$ Privilegiando a análise da ação Saquarema (MATTOS (2004, p. 115-140), tomando como referência os movimentos liberais de 1842 e 1848, enfatiza que, embora prevalecesse "o interesse entre os liberais àquela época de conduzir a política de modo que assegurasse o predomínio de cada grupo em seu âmbito provincial - e que deveria expressar-se numa distribuição tendencialmente mais equilibrada do aparelho de Estado pelo território imperial", a vitória Saquarema acabaria por determinar a predominância de um projeto centralizador para o Estado imperial e estabeleceria uma escala hierárquica em que os interesses Saquaremas se sobrepunham aos dos demais conservadores e dos Luzias. Embora houvesse essa sobreposição de interesses, a questão da construção de uma nação ordenada e civilizada era ponto em comum entre esses dois grupos políticos.
} 
Criava-se, desta forma, uma identidade legitimadora, introduzida pelas instituições dominantes na sociedade, cujo intuito, era o de expandir e de racionalizar a dominação dos grupos dirigentes em relação aos atores sociais. A "boa sociedade" era representada pela classe senhorial que se diferenciava dos plantadores escravistas pelo espaço de dominação exercido. Espaço esse que não se limitava à sua propriedade, ou seja, ao governo da Casa, pelo contrário, atrelava-se ao Estado para construir sua unidade e incorporar novos elementos:

De um lado, a Coroa une aos interesses agrários, mercantis e burocráticos que se expandiam com a lavoura cafeeira os detentores dos monopólios que, de modo e em graus diversos, haviam se constituído nas demais regiões e mesmo na região de agricultura mercantil-escravista, fazendo-os superar, muitas vezes, as atitudes de desconfiança que nutriam em relação ao aparelho de Estado desde o tempo da luta contra a antiga metrópole. Em sua ação, a Coroa procede a uma expansão horizontal da classe senhorial. De outro lado ela atrai para a órbita dos interesses da classe senhorial os elementos que, no Império escravocrata, detêm uma única propriedade, a de suas pessoas, procedendo assim a uma segunda expansão, verticalmente. Entenda-se, todavia, que levar a cabo esta dupla expansão não significa apenas e nem principalmente obter uma submissão, e sim proceder a uma incorporação, a qual se apresentava, nos termos da própria proposta iluminista, como a difusão de uma civilização. (MATTOS, 2004, p. 104).

Para o autor, a Coroa se constituía na "expressão e na forma mais avançada dos interesses da classe em constituição; a Coroa como um partido político não se reduz à figura do Imperador”. (MATTOS, 200, p.104) ${ }^{11}$. Hierarquizando governados, dirigentes e dirigidos e administrando as fissuras e as divergências no interior da classe senhorial; constituiu-se, assim, o fiel da balança do jogo político, o que propiciou a unificação e a homogeneização de seus representantes políticos e legitimou a sua dominação. A homogeneização da classe senhorial se dava via atividades de direção e via sistema de relações em que se inscreviam.

É importante ressaltar que a direção conservadora, a qual, para o autor, foi além dos marcos temporais estabelecidos entre 1834-1860, não era restrita à alta burocracia imperial, estendendo-se ainda:

[...] aos proprietários rurais localizados nas mais diversas regiões e nos mais distantes pontos do Império, mas que orientam suas ações pelos parâmetros fixados pelos dirigentes imperiais, além dos professores, médicos, jornalistas, literatos e demais agentes "não públicos" - um conjunto unificado tanto pela adesão aos princípios da Ordem e Civilização quanto pela ação visando sua difusão. (MATTOS, 2004, p. 15-16).

\footnotetext{
${ }^{11}$ A qualificação da Coroa como partido, definido como um organismo no qual "já tenha se iniciado a concretização de uma vontade coletiva reconhecida e fundamentada parcialmente na ação", foi fundamentada em Gramsci. Ver: Mattos (2004, p. 104).
} 
A "boa sociedade", ao se confundir com a sociedade política, traz para si a tarefa de governar o Estado, constituindo o mundo do governo, que se enxergava não só como naturalmente ordenado, mas também como responsável pela ordenação do conjunto da sociedade. O discurso e as ações ordenadoras da sociedade, por sua vez, remetem-nos ao seu oposto, isto é, o discurso da ordem só encontra eco em uma sociedade que se enxergava, pelo menos para os setores dirigentes, como desordenada. A defesa da ordem é complementada pela noção de desordem.

A massa de homens livres e pobres que não pertenciam ao "mundo do trabalho", e muito menos ao "mundo da ordem", gerava intranquilidade pela tendência à vadiagem e à preguiça, assim como pelas exigências de igualdade e reivindicações que colocavam em risco a "ordem", por meio de sua participação em movimentos como os ocorridos durante o período Regencial ${ }^{12}$.

À medida que o Estado Imperial centralizava as decisões administrativas, promovendo a expansão dos negócios, cobrando mais impostos, regulamentando a moeda, criando instituições de ensino seja de nível primário, secundário ou superior, e monopolizava o uso da força, por meio da reforma da Guarda Nacional, em 1850, da restauração do Exército e da Marinha ${ }^{13}$, aquele constituía-se, gradativamente, no lócus, por excelência, dos debates e das ações que visavam a encaminhar as questões nacionais. Para Carvalho (2008, p. 256-259), o ano de 1850 foi um marco divisório na implantação do Estado Nacional. A derrota dos liberais pernambucanos, em 1848, teria significado o "fim do processo de aceitação da monarquia parlamentar pelas elites rurais", garantindo legitimidade ao sistema ${ }^{14}$.

Discorrer longamente sobre as preocupações de Nabuco com o Brasil do final do XIX, e sobre as interpretações de José Murilo de Carvalho e de Ilmar Rohloff de Mattos sobre o processo de formação da nação brasileira e sobre suas imbricações com a

\footnotetext{
${ }^{12}$ Acerca da conturbado período regencial, ver: Carvalho (2008, p. 250-260). Ver sobre o levante dos Malês em Reis (1986). O medo de levantes escravos no Brasil oitocentista foi analisado por Azevedo (2003).

${ }^{13}$ Segundo Carvalho (2008); o processo de reforma da Guarda Nacional, iniciado em 1840, concluiu o esforço de centralização político-administrativo ao colocar sob a responsabilidade de agentes do governo central o preenchimento dos postos de seus oficiais. Além dessa medida, teria sido imprescindível ao processo de centralização do poder, a Lei Interpretativa do Ato Adicional, em 1840, e a reforma do Código do Processo Criminal, em 1841.

${ }^{14}$ A permanência de um Ministério conservador, desde 1848, teria garantido ao governo força suficiente para tratar de "dois problemas quase intratáveis, embora cruciais para a soberania nacional, para a sobrevivência da classe proprietária e para o próprio Estado: o problema do tráfico, e o problema da estrutura agrária e da imigração". (CARVALHO, 2008, p. 256).
} 
conformação de uma ordem conservadora no país nos serve, aqui, para algumas reflexões e um retorno a Darcy Ribeiro.

Em O povo brasileiro, o autor compreende a unificação do Brasil associada à supressão de toda a identidade étnica discrepante, castigando como separatistas os movimentos que eram meramente republicanos ou anti oligárquicos. A base de formação da sociedade foi a desigualdade, a estratificação, o controle sobre a terra e a mão de obra, seja no período colonial, no Império ou na República, preservando uma ordem conservadora. Compuseram-se estes como elementos homogeneizadores ao que Darcy Ribeiro chamou de "cultura brasileira rústica"15 e foram fundamentais para a transformação das vilas, arraiais e futuras cidades em "criatórios de gente"16, traço comum em todos os momentos de nossa história.

Curiosamente, para Darcy Ribeiro, a manutenção da unidade territorial, consolidada depois da independência, teria sido:

[...] o único mérito indiscutível das velhas classes dirigentes brasileiras. Comparando o bloco unitário resultante da América portuguesa com o mosaico de quadros nacionais diversos a que deu lugar a América hispânica, pode-se avaliar a extraordinária importância desse feito. (RIBEIRO, 2006, p. 20).

Consideramos "curiosa" a afirmação do autor pela análise que ele faz desse próprio processo e de seus resultados, conforme exposto acima: estratificação, repressão, dizimação de etnias e vitória de um projeto político excludente em suas origens e que teria prevalecido em todos os momentos de nossa história. Compreendemos então que, de uma mesma matriz, conservadora e excludente, surgiram duas homogeneidades: uma primeira, que congregou a elite em torno da preservação dessa matriz, e uma segunda que teria dado sentido ao título "povo brasileiro": compartilhar entre si, ao longo de sua história, as mazelas de uma sociedade fortemente estratificada e classista. Tão classista que, na visão do autor, os brasileiros não são separados pelo preconceito racial e, sim, pela estratificação de classes. Resulta, assim,

\footnotetext{
${ }^{15}$ Por cultura brasileira rústica, o autor compreende a cultura crioula, a cabocla, a sertaneja, a caipira e os Brasis sulinos. Essa diversidade cultural teria sido fruto da necessidade de adaptações regionais, das especializações funcionais da produção e seus correspondentes gêneros de vida e da imigração. Por outro lado, o fator comum a todas elas seria um processo marcante de controle sobre a terra e sobre a mão-deobra. (RIBEIRO, 2006).

${ }^{16}$ Originalmente a expressão aparece em $O$ povo brasileiro (2006, p.384), em referência aos sertões pastoris do Nordeste e às estâncias do Sul. Estas seriam criatórios de gado e seus arraiais, em função do controle sobre a terra e de um processo de urbanização sem industrialização, criatórios de gente, ou seja, multiplicaram-se nas pequenas e grandes cidades os subocupados, os mendigos e as prostitutas.
} 
que a propagandeada unidade nacional só se consolidou em função do sucesso de um projeto arbitrário e autoritário por parte da elite nacional. Resta-nos então questionar não por que o Brasil não deu certo e sim por que os brasileiros não deram certo.

Note-se que estamos compreendendo aqui que a leitura do autor do processo histórico brasileiro nos permite estabelecer essa condição estanque: o povo brasileiro versus o Estado e a elite dirigente, seja esta política ou econômica. Na verdade essa percepção estanque permeia, até mesmo em termos do senso comum, o imaginário nacional. Afinal, em todas as eleições "o povo" não soube votar, por isso políticos corruptos povoam o Congresso Nacional. Entidade à parte, "o povo" permanece ainda hoje descolado e deslocado de um Estado que engatinha no sentido de incorporá-lo efetivamente em uma prática política que, dispensando o assistencialismo, promova a sua inserção como cidadão de primeira classe, alterando definitivamente a face excludente de nossa sociedade. Quem somos nós afinal, já que não nos compreendemos como povo? E se não nos compreendemos como povo, voltamos a uma proposição chave do trabalho de Darcy Ribeiro: conhecer para intervir e influir. Por mais que os “intérpretes do Brasil" tenham sido brilhantes em suas análises, falta aos brasileiros reconhecerem-se nelas e escolherem o caminho a seguir na conformação de uma sociedade que deixe para trás os ranços conservadores e autoritários. Esse talvez seja um dos maiores desafios da atualidade do Brasil. Afinal, o sucesso econômico da última década, acreditamos, encobriu os males sociais com o véu da prosperidade e com a crença generalizada de que a nação cumpriu seu papel histórico: fazer parte das "Nações Civilizadas".

\section{Conclusão}

Neste ponto unimos as falas de Nabuco e Darcy Ribeiro. Tempos diferentes ligados por uma linha de continuidade na qual palavras como reforma, moralização e cooperação ainda ocupam espaço significativo no que seria o ideal de nação. Se para o primeiro o fim da escravidão solucionaria todos os males; para o segundo, a ponte a dar sentido e unidade às "duas nações", a da elite e a do povo, seriam a educação e fatalmente a revolução tecnológica desta decorrente. Aqui Darcy Ribeiro se conecta as análises de José Murilo de Carvalho e de Ilmar Rohloff. Se para as elites a educação de si própria foi fundamental como elemento conformador de uma identidade, primeiro de 
grupo e depois de povo, servindo à manutenção de uma dada ordem, nada como reverter o quadro, utilizando-a (a educação) como recurso para tal.

A educação constituir-se-ia o caminho a ser trilhado para a formação e a consolidação de um povo ciente de sua cidadania, para uma estrutura de Estado que atuasse a serviço do coletivo, e, concomitantemente, inserir a nação no rol não apenas dos mais ricos, mas efetivamente dos mais civilizados. E aí retomamos a coerência que vinculou o homem ao intelectual e ao político e, principalmente, ao sonho. Abordar a atuação de Darcy Ribeiro como educador é tarefa dispensável. Polêmicas à parte, mais que um "intérprete do Brasil”, foi um homem de ações. Se não o revolucionário da juventude comunista, o reformador que compreendeu que apenas o conhecimento de si e das alteridades, por meio da educação, promoveria o fim de nosso "doce" apartheid social. 


\section{REFERÊNCIAS}

ANDRADE, Marcos Ferreira. Unidade, autonomia regional e construção do Estado Nacional brasileiro: a participação das elites do sul de Minas Gerais. In: GONÇALVES, Andréa Lisly; ARAUJO, Valdei Lopes (Org.). Estado, região e sociedade: contribuições sobre história social e política. Belo Horizonte: Argumentum, 2007.

AZEVEDO, Célia Maria Marinho de. Abolicionismo: Estados Unidos e Brasil, uma história comparada (século XIX). São Paulo: Annablume, 2003.

CARVAlHO, José Murilo de. A construção da Ordem: a elite política imperial. Teatro de sombras: a política imperial. Rio de Janeiro: Civilização Brasileira, 2008.

CARVALHO, José Murilo de. A formação das almas: o imaginário da república no Brasil. São Paulo: Companhia das Letras, 2008.

CASTRO, Hebe Maria Mattos de. Laços de família e direitos no final da escravidão. In: ALENCASTRO, Luis Felipe de. (Org.). História da vida privada no Brasil: Império. São Paulo: Companhia das Letras, 2008.

CHALHOUB, Sidney. Trabalho, lar e botequim: o cotidiano dos trabalhadores do Rio de Janeiro da Belle Époque. São Paulo: Editora Brasiliense, 1986.

COSENTINO, Daniel do Val. O olhar das autoridades: projetos e processo para a transição do trabalho escravo para o trabalho livre na Província de Minas Gerais. Anais do XIII Seminário sobre a Economia Mineira (CD). Diamantina: CEDEPLAR UFMG, 2008.

GEBARA, Ademir. O mercado de trabalho livre no Brasil. São Paulo: Editora Brasiliense, 1986.

GRINBERG, Keila. O fiador dos Brasileiros: cidadania, escravidão e direito civil no tempo de Antonio Pereira Rebouças. Rio de Janeiro: Civilização Brasileira, 2002.

HESPANHA, Antonio Manuel. Governo, elites e competência social: sugestões para um entendimento renovado da história das elites. In: BICALHO, Maria Fernanda; FERLINI, Vera Lúcia Amaral (Org.). Modos de governar: ideias e práticas políticas no Império português, séculos XVI a XIX. São Paulo: Alameda, 2007.

LAMOUNIER, Maria Lúcia. Da escravidão ao trabalho livre: a lei de locação de serviços de 1879. São Paulo: Papirus, 1988.

MATTOS, Ilmar Rohloff de. O tempo Saquarema: a formação do Estado Imperial. São Paulo: HUCITEC, 2004.

NABUCO, Joaquim. O Abolicionismo. Rio de Janeiro: Nova Fronteira; São Paulo: Publifolha, 2000. 
REIS, José Carlos. As identidades do Brasil 1: de Varnhagen a FHC. Rio de Janeiro: Editora FGV, 2007.

REIS, José Carlos. As identidades do Brasil 2: de Calmon à Bonfim. Rio de Janeiro: Editora FGV, 2006.

RIBEIRO, Darcy. O processo civilizatório: etapas da evolução sócio-cultural. Rio de Janeiro: Civilização Brasileira, 1968.

RIBEIRO, Darcy. As Américas e a civilização: a integração das populações indígenas no Brasil moderno. Rio de Janeiro: Civilização Brasileira, 1970.

RIBEIRO, Darcy. O povo brasileiro. São Paulo: Companhia das Letras, 2006.

SCHWARCZ, Lilian Moritz. O Espetáculo das raças: cientistas, instituições e questão racial no Brasil, 1870-1930. São Paulo: Companhia das Letras, 2001.

SILVA, Ana Rosa Cloclet da. Construção da Nação e escravidão no pensamento de José Bonifácio (1783-1823). Campinas: Editora da Unicamp, 1999. 